\title{
Níveis de irrigação na cultura do Kalanchoe cultivado em ambiente protegido
}

\author{
Water levels in the culture of kalanchoe grown in protected
}

\author{
Ana Rita Costenaro Parizi ${ }^{{ }^{*}}$ Marcia Xavier Peiter ${ }^{\mathrm{II}}$ Adroaldo Dias Robaina ${ }^{\mathrm{II}}$ \\ Fátima Cibele Soares ${ }^{I}$ Gisele Aparecida Vivan' ${ }^{I}$ Cleiton José RamãoII
}

\section{RESUMO}

\begin{abstract}
O estudo do desenvolvimento foliar é de grande importância para a avaliação do crescimento $e$ desenvolvimento das plantas. O objetivo deste trabalho foi quantificar as consequências dos diferentes níveis do manejo de água de irrigação sobre o crescimento foliar e o número de folhas do Kalanchoe. O delineamento experimental utilizado foi inteiramente casualizado, com oito tratamentos de irrigação (15; 13; 11; 9; 8; 6; 4 e 2mm) e dez repetições. A área foliar das plantas foi calculada por meio do produto do comprimento e da largura de cada folha, multiplicada pelo coeficiente de 1,1134. Os resultados mostraram que as lâminas de irrigação entre 6 e 9mm apresentaram maior crescimento foliar e maior número de folhas por planta. A máxima eficiência técnica foi encontrada com lâminas de 6,68 e 8,59mm, para área foliar e número de folhas por planta, respectivamente. Em condições de déficit hídrico, o Kalanchoe reduz expressivamente sua elongação foliar transversal em relação à longitudinal.
\end{abstract}

Palavras-chave: crescimento foliar, flor-da-fortura, lâminas de irrigação.

\section{ABSTRACT}

The research about the leaf development is very important to evaluate the plants growth and development. The objective of this research was to verify the different level consequences about the irrigation water manner in the leaf growth and the number of the Kalanchoe leaves. The experimental search used was completely randomized, with eight treatments, they consisted in 15;13;11; 9; 8; 6; 4 e $2 \mathrm{~mm}$ irrigation in ten repetitions. The plants leaf area was calculated by the area of each leaf, multiplied by the coefficient of 1.1134. The results showed that the irrigation length between 6 and $9 \mathrm{~mm}$ showed a bigger leaf growth and more leaves in each plant; the biggest technical efficiency was found with 6.68 and
$8.59 \mathrm{~mm}$ length, to each leaf area and the leaves number in leaf/plant, respectively. In a water condition deficit the Kalanchoe reduces a lot the leaf transversal growth related to the longitudinal.

Key words: leaf growth, fortune flower, irrigation length.

\section{INTRODUÇÃO}

O Kalanchoe está entre as diversas espécies de flores cultivadas com fins comerciais que apresentam ótima aceitação no mercado (Kalanchoe blossfeldiana Poelln.) (AGRONLINE, 2008). Essa espécie, originária da Ilha de Madagascar e pertencente à família Crassulaceae, caracteriza-se por ser uma planta suculenta, contendo numerosas flores com variadas pigmentações (LORENZI \& SOUZA, 2000). Pode ser produzida em condições de cultivo em ambiente protegido ou a céu aberto, sendo comercializada em vasos e em mudas, destinadas ao plantio em floreiras e canteiros.

A cultura do Kalanchoe desenvolvida em vasos necessita de grande quantidade de água e fertilizantes. Segundo BELLÉ (2000), em plantas ornamentais de vaso, entre as tarefas mais importantes para a produção, encontra-se a irrigação, em especial em cultivos em ambiente protegido, onde as plantas não recebem água das chuvas e o aporte de água se dá exclusivamente por meio das irrigações.

IPrograma de Pós-graduação em Engenharia Agrícola, Universidade Federal de Santa Maria (UFSM), 97105-900, Santa Maria, RS, Brasil. E-mail: anaparizi@gmail.com. *Autor para correspondência.

IDepartamento de Engenharia Rural, UFSM, Santa Maria, RS, Brasil.

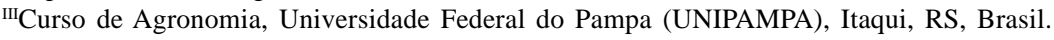


A quantidade de água disponível no substrato é um dos fatores mais importantes para a cultura, pois está relacionada com o desenvolvimento vegetativo e a produtividade da cultura (KÄMPF, 2000). O déficit hídrico refletirá em desenvolvimento lento e baixa produtividade, enquanto que o excesso favorecerá o aparecimento de doenças, prejudicando o desenvolvimento da cultura. Conhecendo a quantidade de água a ser fornecida às plantas, é possível garantir um manejo mais eficiente da irrigação, reduzindo custos, evitando excessos de água e melhorando a qualidade da produção (VIEIRA et al., 2000).

De uma forma geral, as plantas submetidas a déficits hídricos apresentam sintomas característicos, tais como enrolamento, menor elongação das folhas e entrenós, mudança na pigmentação das folhas, epinastia, menor ângulo de inserção das folhas, etc. No entanto, quando a planta exterioriza a maioria dessas características, o efeito do déficit no solo já causou redução significativa no potencial produtivo da cultura (SANTOS \& CARLESSO, 1999). Cita-se ainda o decréscimo da área foliar, o fechamento dos estômatos, a aceleração da senescência e a abscisão das folhas como respostas proeminente das plantas ao déficit hídrico (MCCREE \& FERNÁNDEZ, 1989; TAIZ \& ZEIGER, 1991).

A determinação da área foliar é um dos principais parâmetros a serem analisados no crescimento vegetal das plantas, visto estar relacionada com diversos processos fisiológicos, tais como fotossíntese, respiração e transpiração (COSTA, 1999), além de servir para estimar a necessidade hídrica da cultura (ALLEN et al., 1996). Sua avaliação, durante todo o ciclo da cultura, é de extrema importância para que se possa modelar o crescimento e o desenvolvimento da planta e, em consequência, a produtividade e a produção total da cultura (TERUEL, 1995).

Outro parâmetro a ser avaliado é a redução do número de folhas em plantas sob estresse hídrico, podendo ser considerada como uma estratégia de sobrevivência em condições adversas, para evitar a perda de água por transpiração (KOZLOWSKI, 1976). De acordo com OLIVEIRA \& SILVA(1990), a irrigação pode ser utilizada para ajustar o índice de área foliar e reduzir a senescência das plantas, possibilitando um desenvolvimento equilibrado do dossel vegetativo. Para AZIZ \& LAHRER (1995), o ajustamento osmótico em função da água disponível está altamente associado com a morfologia externa dos vegetais.

O objetivo deste trabalho foi quantificar os efeitos das diferentes lâminas de irrigação sobre o crescimento foliar e o número de folhas do Kalanchoe.

\section{MATERIAL E MÉTODOS}

O experimento foi conduzido no ano agrícola 2001/2002, em estufa plástica convencional, na área experimental do Curso de Engenharia Agrícola da Universidade Regional Integrada do Alto Uruguai e das Missões,(URI), Campus de Santiago, Rio Grande do Sul (RS). O município de Santiago localiza-se nas coordenadas geográficas 2909'50”S, 5451”32”W e altitude de 439m acima do nível do mar, apresentando clima subtropical úmido, temperaturas variando entre 13 e $21^{\circ} \mathrm{C}$, média térmica de $17,9^{\circ} \mathrm{C}$, ventos predominantes na direção leste com velocidades médias entre 25 e $30 \mathrm{~km} \mathrm{~h}^{-1}$ e precipitação pluviométrica de 1.919mm ano-1 (GOMES, 2004).

A estufa na qual o experimento foi conduzido apresentava as seguintes características: 6,0x40,0m, pé direito de $3,5 \mathrm{~m}$, altura central de $4,4 \mathrm{~m}$, colunas de concreto, arcos treliçados de $300 \mathrm{~mm}$, dois portões, sendo um em cada cabeceira, revestimento da coberta e das laterais com filme transparente aditivado antirraio UV e espessura $150 \mu \mathrm{m}$ e espaçamento de $4,0 \mathrm{~m}$ entre vãos.

O Kalanchoe da cultivar 'Gold Jewel' foi cultivado em vasos de plástico de $6 \mathrm{~cm}$ de altura e preenchido com substrato industrializado para floricultura. Esses vasos estavam dispostos em bancadas de $3 \mathrm{~m}$ de comprimento, $1 \mathrm{~m}$ de largura e $1 \mathrm{~m}$ de altura em relação à superfície do solo, no interior da estufa. O substrato utilizado caracterizou-se por apresentar elevada percentagem de matéria orgânica, sendo esterelizado previamente com $\mathrm{pH}$, variando entre 5,5 e 6,0 e espaço de aeração de aproximadamente de $10 \%$.

No substrato, foram determinadas a altura de lâmina de água máxima (capacidade de campo ou limite superior de disponibilidade hídrica) e a altura de lâmina remanescente (ponto de murcha permanente ou limite inferior de disponibilidade hídrica). Considerouse como capacidade de vaso (CV) a quantidade de água que o substrato reteve e foi disponível à planta após cessar o processo de drenagem, com a parte superior do vaso coberta com lona plástica. A quantidade de água remanescente foi a quantidade de água restante no substrato após morte por murcha permanente de uma planta adulta de Kalanchoe. A partir do limite superior e do limite inferior de disponibilidade hídrica do substrato, calculou-se a CV por meio da equação: $C V=L s-L i$, em que CV é a capacidade de vaso (mm); Ls é o limite superior de disponibilidade hídrica do substrato (mm) e Li é o limite inferior de disponibilidade hídrica do substrato (mm).

A quantidade máxima de água que o substrato reteve foi de $80 \mathrm{ml}$. Com base nesse dado, 
determinaram-se as lâminas de irrigação, as quais foram aplicadas diariamente com equivalência de 100, 90, 75, $60,50,40,25$ e $12 \%$ da CV, o que corresponde a 15; 13; 11; 9; 8; 6; 4 e 2mm, respectivamente. As aplicações de água foram feitas manualmente com proveta graduada de $100 \mathrm{ml}$.

O consumo de água do kalanchoe foi determinado por meio da equação do balanço hídrico, conforme a expressão: $E$ tr $=\sum_{L}^{L} M_{i}-\sum^{L} M_{i+1}+I-D$, em que Etr é a evapotranspiração real da planta em vaso, em um intervalo de tempo $\Delta t$ de dois e três dias; $M_{i}$ é a massa de substrato e água contida no vaso, no início do intervalo de tempo $(\Delta \mathrm{t})$ considerado; i é o intervalo de tempo $(\Delta \mathrm{t})$ considerado para o balanço; $\mathrm{M}_{\mathrm{i}+1}$ é a massa de substrato e água remanescente no final do intervalo de tempo $(\Delta \mathrm{t})$ considerado; I é a irrigação aplicada no vaso no intervalo de tempo $\Delta \mathrm{t}$; e D é a percolação (ou drenagem) que eventualmente possa ocorrer no mesmo intervalo de tempo $\Delta$ t. A variação do armazenamento de água no vaso $\left(\mathrm{M}_{i}-\mathrm{M}_{i+1}\right)$ foi realizada por meio da pesagem dos vasos, em balança com precisão de $0,01 \mathrm{~g}$.

O delineamento experimental utilizado foi inteiramente casualizado, com oito doses de irrigação (tratamentos) e 10 repetições, totalizando 80 unidades experimentais (80 plantas em vasos). Realizou-se o plantio por estaquia em bandejas, e o transplante para os vasos foi realizado no momento em que as plântulas atingiram três folhas.

As medidas de área foliar foram feitas pela determinação de comprimento (C) e largura (L) máxima de cada folha e tiveram início após o transplante das mudas para os vasos. As determinações foram realizadas durante todo o ciclo da cultura (160 dias), três vezes por semana. A área foliar das plantas foi calculada pela equação: $A F=C^{*} L^{*} 1.134$, em que C é a medida do comprimento, $L$ é a medida da largura e
1,134 é o fator de correção (PEITER et al., 2006). Foi determinada a elongação foliar longitudinal e transversal por meio das seguintes equações, respectivamente: $E L=C_{i}-C_{i-1}$, em que $C_{i}$ é comprimento da folha no dia da determinação e $C_{i-1}$ é o comprimento da folha no dia anterior à determinação; $E T=L_{i}-L_{i-1}$, em que $L_{i}$ é a largura da folha no dia da determinação e $L_{i-l}$ é a largura da folha no dia anterior à determinação.

Os resultados foram submetidos à análise de variância e de regressão para o ajuste da equação de maior grau significativo. Após a determinação da equação, foi calculada a máxima eficiência técnica (MET), para a obtenção da variável independente (área foliar e número de folhas), para a qual a variável dependente (lâmina de irrigação) é máxima.

\section{RESULTADOS E DISCUSSÃO}

A tabela 1 apresenta as lâminas de irrigação aplicadas ao longo do ciclo da cultura e os valores médios de área foliar e número de folhas, para os diferentes tratamentos. As lâminas de irrigação influenciaram, significativamente, a área foliar e o número de folhas por planta $(P<0,05)$. Para ambas as variáveis, foi determinado o ajuste de equação de terceiro grau, visto que esta possuir maior grau significativo.

Na figura 1a, são apresentados os valores da área foliar em função das lâminas de irrigação aplicadas nos diferentes tratamentos. Pode-se observar que os maiores valores de área foliar encontram-se entre os tratamentos com lâminas de 6 a $9 \mathrm{~mm}$. Nos demais tratamentos ( 2 a $4 \mathrm{~mm}$ e 11 a $15 \mathrm{~mm}$ ), foram encontrados menores valores de área foliar, o que pode ser atribuído ao déficit e excesso hídrico, respectivamente. PEITER et al, (2006) determinaram o consumo hídrico da florda-fortuna sob diferentes lâminas de irrigação e as

Tabela 1 - Valores de lâminas totais de irrigação aplicadas ao longo do ciclo do kalanchoe, área foliar e número de folhas por planta, sob condições de oito diferentes lâminas de irrigação aplicadas em estufa plástica - Santiago, RS, 2001/2002.

\begin{tabular}{|c|c|c|c|c|}
\hline Tratamento & $\begin{array}{l}\text { Lâmina de irrigação } \\
\text { (mm) }\end{array}$ & $\begin{array}{l}\text { Lâmina total aplicada } \\
\text { (mm) }\end{array}$ & $\begin{array}{l}\text { Área foliar } \\
\quad\left(\mathrm{cm}^{2}\right)\end{array}$ & Número de folhas \\
\hline $12 \%$ & 2 & 32 & 191,6 & 9,4 \\
\hline $25 \%$ & 4 & 64 & 226,7 & 9,4 \\
\hline $40 \%$ & 6 & 96 & 239,8 & 10,0 \\
\hline $50 \%$ & 8 & 128 & 250,0 & 13,1 \\
\hline $60 \%$ & 9 & 144 & 258,7 & 13,1 \\
\hline $75 \%$ & 11 & 176 & 215,8 & 12,8 \\
\hline $90 \%$ & 13 & 208 & 195,7 & 12,7 \\
\hline $100 \%$ & 15 & 240 & 134,7 & 10,6 \\
\hline $\mathrm{F}$ & & & $6,17 *$ & $6,27 *$ \\
\hline $\mathrm{CV}(\%)$ & & & 23,4 & 18,8 \\
\hline
\end{tabular}

*significativo a 5\% de probabilidade.

Ciência Rural, v.40, n.4, abr, 2010. 


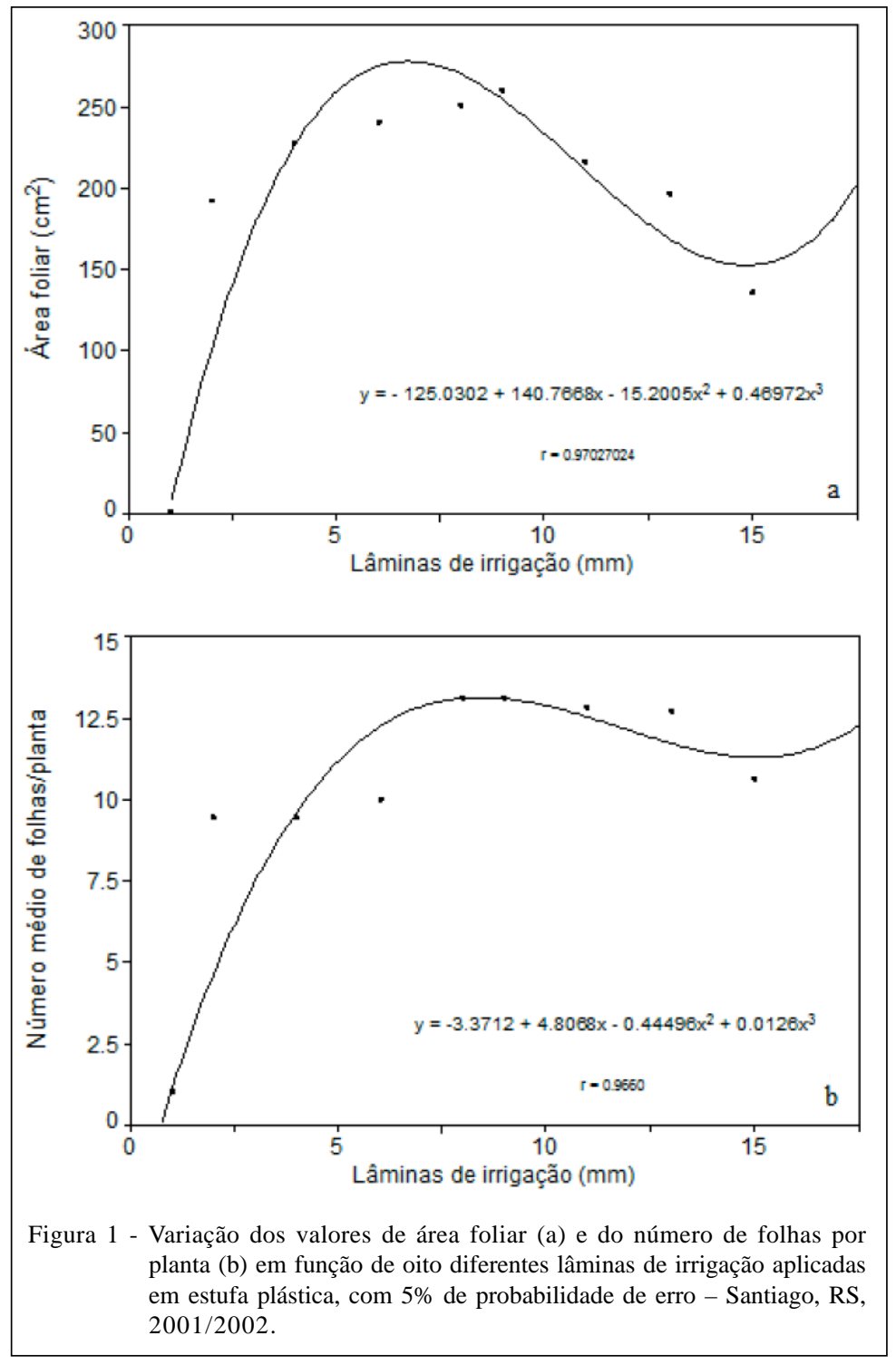

consequências dessas estratégias sobre a produção, concluindo que o nível ótimo de irrigação para a florda-fortuna da cultivar 'Gold Jewel' cultivada em estufa, na região de Santiago, foi de, aproximadamente, $10 \mathrm{~mm}$ dia $^{-1}$, o que corresponde a uma aplicação de aproximadamente $70 \%$ da CV nas condições deste trabalho.

Por meio da equação de ajuste, observouse que o ponto de máxima eficiência técnica, obtida das derivadas da função ajustada (Figura 1a), corresponde à lâmina de $67 \mathrm{~mm}$, cuja área foliar correspondente foi de $267,4 \mathrm{~cm}^{2}$.

A figura $1 \mathrm{~b}$ apresenta o modelo matemático ajustado para número médio de folhas por planta em função das lâminas de irrigação aplicadas. Pode-se observar que o número médio de folhas por planta teve seu pico máximo de crescimento nas plantas que recebiam lâminas de irrigação entre 8 e $9 \mathrm{~mm}$. Por meio do modelo matemático ajustado, foi determinado o ponto de máxima eficiência técnica, sendo este a lâmina de 8,6mm cujo número de folhas corresponde a 12,9.

O estresse hídrico reduziu o número de folhas, observando-se através da análise da variância $(\mathrm{P}<0,05)$ diferença significativa entre os diferentes tratamentos. PEREIRA (2003), trabalhando com crisântemo sob diferentes níveis de reposição de água (40, 60, 80 e 100\% de reposição de água), observaram que o número de folhas por planta foi reduzido nos tratamentos com menores percentagens de reposição hídrica. A figura 2 apresenta o comportamento da área foliar, nos diferentes tratamentos ao longo do ciclo da cultura. Observa-se que, à medida que a cultura se 
desenvolveu, a área foliar apresenta tendência de aumento, tendendo à estabilização e apresentando ajuste linear para todos os tratamentos. Esses resultados estão de acordo com os obtidos por VIANA et al. (2004), trabalhando com diferentes doses de irrigação em crisântemo. A tendência de estabilização

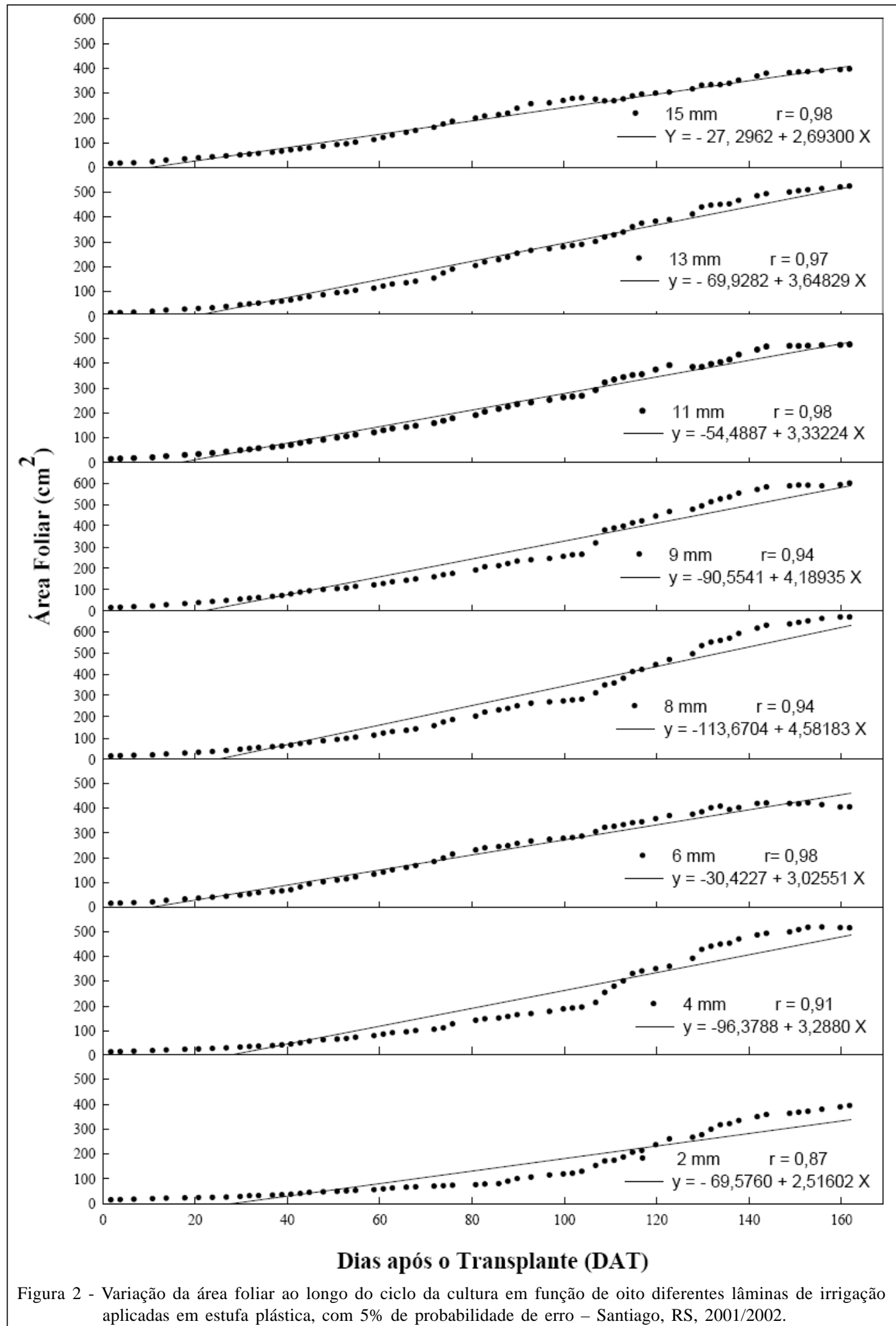

Ciência Rural, v.40, n.4, abr, 2010. 
ocorre em razão de as plantas apresentarem senescência de folhas mais velhas e estarem em fase de florescimento. Nesse período, a área foliar já não mais se expressa, pois as reservas de desenvolvimento da planta são para o desenvolvimento reprodutivo. Esse resultado está de acordo com o encontrado por FURLAN et al. (1998).

Verifica-se que o tratamento com maior área foliar foi o tratamento com 9mm, seguido do tratamento com $8 \mathrm{~mm}$, apresentando um crescimento mais acentuado com relação aos demais. $\mathrm{O}$ tratamento com $2 \mathrm{~mm}$ apresentou menor crescimento, seguido do tratamento com 4mm. Observa-se também que o tratamento com 15mm (maior lâmina de água) apresentou um crescimento inicial contínuo, até aproximadamente 100DAT, posteriormente o crescimento foi menor, mostrando-se semelhante ao tratamento com $2 \mathrm{~mm}$ (menor quantidade de água aplicada). Esse fato comprova que o excesso hídrico tanto quanto o déficit apresenta redução no crescimento da planta. RÊGO et al. (2004), trabalhando com níveis de irrigação de 50, 75, 100 e 125\% da evaporação medida em tanque classe “ $A$ ” (ECA), encontraram decréscimos no diâmetro de hastes, comprimento da haste e peso da haste, a partir do nível de $100 \%$ da ECA.

Por meio das equações de correlação apresentadas na figura 3, pode-se observar que os

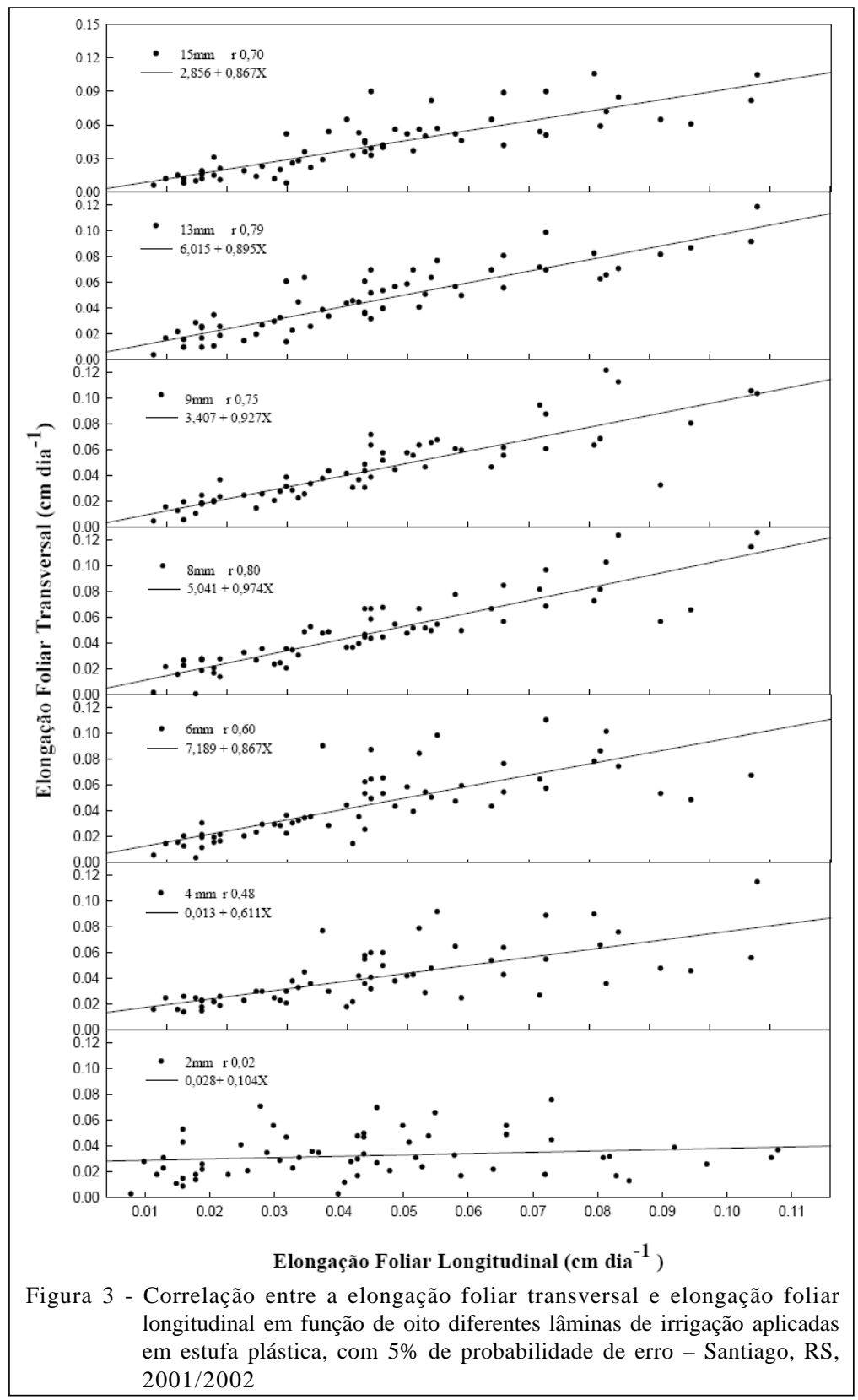

Ciência Rural, v.40, n.4, abr, 2010. 
tratamentos com 8, 9, 13 e 15mm apresentaram boa correlação entre a elongação transversal e longitudinal da área foliar, com coeficientes de determinação superiores a 0,70 , ou seja, as folhas apresentavam elongação transversal e longitudinal quase que na mesma escala de crescimento, não indicando diferença expressiva entre as elongações. De acordo com GARCIA (1989), valores de coeficiente de correlação superiores a 0,70 indicam bons ajustes. Os menores valores de correlação foram observados nos tratamentos com lâminas de irrigação de 2, 4 e $6 \mathrm{~mm}$.

A partir desses resultados, pode-se observar que as plantas, quando submetidas ao déficit hídrico, apresentam uma redução expressiva no crescimento foliar transversal, resultando em um crescimento desproporcional, ou seja, a folha cresce longitudinalmente e estaciona seu crescimento transversalmente. As plantas que foram submetidas a $8 \mathrm{~mm}$ de irrigação apresentaram a melhor correlação entre as elongações, ou seja, as plantas cresciam longitudinalmente e transversalmente quase que nas mesmas proporções.

\section{CONCLUSÕES}

A análise de crescimento do kalanchoe revelou que a área foliar e o número de folhas por planta foram afetados pelas condições hídricas do substrato. Nessas condições, ocorre redução expressiva da elongação foliar transversal em relação à longitudinal das folhas, resultando em folhas estreitas e longas, fora do padrão da qualidade atribuída para plantas ornamentais.

\section{REFERÊNCIAS}

AGRONLINE. Brasil tem 250 tipos de flores e setor movimenta mais de R\$ 2 bilhões. Brasil. Acessado em: 11 de set. 2008. Online. Disponível em: <http://www,agronline,com,br/ agronoticias/noticia,php?id=3385 $>$.

ALLEN, R.G. et al. Proposed revision to the FAO: procedure for estimating crop water requeriments. In: INTERNATIONAL SYMPOSIUM ON IRRIGATION OF HORTICULTURAL, 1996, Chania. Proceedings... Leven: ISHS, 1996. V.2, p.1749.

AZIZ, A. LARHER, F. Changes in polyamine titers associated with the proline response andosmotic adjustment of rape leaf disc submitted to osmotic stresses. Plant Science, Limerick, v.112, n.2, p.175-186, 1995.

BELLÉ, S. Irrigação de plantas ornamentais. In: PETRY, C. Plantas ornamentais: aspectos para a produção. Passo Fundo, UPF, 2000. p.63-68.
COSTA, M.C. Efeitos de diferentes lâminas de água com dois níveis de salinidade na cultura do meloeiro. 1999. 115f. Tese (Doutorado em Agronomia) - Universidade Estadual de São Paulo, Botucatu, SP.

FURLAN, R.A. et al. Consumo de água pela cultura do crisântemo envasado sob condições de casa de vegetação. Revista Brasileira de Engenharia Agrícola e Ambiental. Campina Grande. v.2, n.1, p.52-55, 1998. Disponível em: $<$ http://www.agriambi.com.br/revista/v2n1/052.pdf $>$. Acesso em: 30 de ago. 2009.

GARCIA, C.H. Tabelas para classificação do coeficiente de variação. Piracicaba: Instituto de Pesquisas e Estudos Florestais - Escola Superior de Agricultura "Luiz de Queiroz", 1989. 12p. (Circular técnica, 171).

GOMES, A.C. Caracterização climática de Santiago, RS para fins agrícolas. 2004. 25f. Monografia (Especialização em Ciências Ambientais) - Universidade Regional Integrada do Alto Uruguai e das Missões, Santiago, RS.

KÄMPF, A.N. Produção comercial de plantas ornamentais. Guaíba: Agropecuária, 2000. 254p.

LORENZI, H.; SOUZA, H.M. Plantas ornamentais do Brasil. Nova Odessa: Plantarum, 2000. 1088p.

KOZLOWSKI, T.I. Water supply and leaf shedding. In: Water stress and plant growth. New York: Academic, 1976. N.4, p.191-222.

MCCREE, K.J.; FERNÁNDEZ, C.J. Simulation model for studyng physiological water stress responses of whole plants. Crop Science, Madison, v.29, n.2, p.353-360, 1989. Disponível em: <http://crop.scijournals.org/cgi/content/abstract/ 29/2/353>. Acesso em: 24 de jun. 2008.

OLIVEIRA, F.A.; SILVA, J.J.S. Evapotranspiração, índice de área foliar e desenvolvimento radicular do feijão irrigado. Pesquisa Agropecuária Brasileira, Brasília, v.25, n.3, p.317-322, 1990.

PEITER, M.X. et al. Modelo para determinação da área foliar de Kalanchoe blossfeldiana Poelln. Ciência Rural, Santa Maria, v.36, n.6, p.1739-1746, 2006. Disponível em: <http:/ / w w w. s c i e l o.b r/ s c i e l o.p h p ? p i d = S 0103 84782006000600011\&script=sci_arttext>. Acesso em: 25 de maio 2009. Doi: 10.1590/S0103-84782006000600011.

PEREIRA, J.R.D. et al. Efeitos da época de suspensão da fertirrigação e níveis de reposição de água na cultura do crisântemo (dendranthema grandiflora). Ciência Agrotecnica, Lavras, v.27, n.3, p.658-664, 2003.

RÊGO, J.L. et al. Efeitos de níveis de irrigação sobre a cultura do crisântemo. Revista Ciência Agronômica, Fortaleza, v.35, n.2, p.302 - 308, 2004.

VIANA, T.V.A. et al. Efeitos de níveis de irrigação sobre o índice de área foliar, a matéria seca e o desenvolvimento da inflorescência da cultura do crisântemo. Revista Irriga, Botucatu, v.9, n.3, p.248-255, 2004. Disponível em: <http:// 200.145.141.142/revistas/irriga/include/getdoc.php?id=424>. Acesso em: 15 de out. 2009. 
VIEIRA, G.H.S. et al. Influência de diferentes lâminas de irrigação nos parâmetros de crescimento do cafeeiro na região de Viçosa, MG. In: SIMPÓSIO DE PESQUISA DOS CAFÉS DO BRASIL, 2000, Poços de Calda, MG. Resumos... Poços de Caldas: Minasplan, 2000. p.879-881.

SANTOS, R.F.; CARLESSO, R. Déficit hídrico e os processos morfológico e fisiológico das plantas. Revista Brasileira Engenharia Agrícola e Ambiental, Campina Grande, v.2, n.3, p.287-294, 1999. Disponível em: <http://www.agriambi.com.br/ revista/v2n3/287.pdf>. Acesso em: 14 de maio 2009.

TAIZ, L.; ZEIGER, E. Plant physiology. Califórnia: Benjamim/ Cummings, 1991. 559p.

TERUEL, D.A. Modelagem do índice de área foliar de cana-de-açúcar em diferentes regimes hídricos. 1995. 93f. Dissertação (Mestrado em Agronomia) - Escola Superior de Agricultura "Luiz de Queiroz”, Piracicaba, SP. 